\title{
College Women's Self-Leadership Stereotypes as a Function of Prime Similarity and Motherhood Information
}

\author{
Susan Anne Basow*, Emily Crawford \\ Department of Psychology, Lafayette College, Easton, USA \\ Email address: \\ Basows@lafayette.edu (S. A. Basow), emcrawford9070@gmail.com (E. Crawford) \\ ${ }^{*}$ Corresponding author
}

To cite this article:

Susan Anne Basow, Emily Crawford. College Women's Self-Leadership Stereotypes as a Function of Prime Similarity and Motherhood Information. Psychology and Behavioral Sciences. Vol. 8, No. 1, 2019, pp. 15-25. doi: 10.11648/j.pbs.20190801.13

Received: December 26, 2018; Accepted: January 22, 2019; Published: February 21, 2019

\begin{abstract}
The goal of the study was to understand under what circumstances exposure to primes of women leaders can influence young women's implicit and explicit identification with leadership gender stereotypes. Previous research has emphasized the importance of perceived similarity in terms of personality traits; the current study explored whether adding information regarding the role models' motherhood status facilitated or impaired such models' inspirational potential. Eightyseven college women in the U.S. participated in the 2 X 2 design in which fabricated feedback indicated whether participants' gendered personality traits were similar or dissimilar to six successful women role models, presented either as mothers or with no mention of mother status. As expected, exposure to the successful women leaders produced counterstereotypic implicit selfleader associations only in the similar mother-mentioned condition. That is, only the participants who were told they had similar traits to the women leaders who were mothers associated themselves with the agentic (counterstereotypical) traits of typical leaders. Explicit self-stereotypes were not influenced by either manipulation unless participants accepted the (false) feedback regarding (dis)similarity. Discussion emphasized the importance of perceived similarity as mediating the effectiveness of exposure to successful role models and the value of including information about the motherhood status of such models, at least for young women.
\end{abstract}

Keywords: Role Models, Implicit Stereotypes, Leadership Stereotypes, Gender Stereotypes, Motherhood, Implicit Attitudes

\section{Introduction}

Despite women in the United States earning approximately $60 \%$ of all undergraduate and master's degrees, nearly half of law and medical degrees, and over a third of MBAs [1], women still are underrepresented in leadership positions, especially in male-dominated fields. Women make up only $6 \%$ of Fortune 500 Company CEOs $(2 \%$ in the financial services industry), only $20 \%$ of the management positions on corporate boards, and fewer than $20 \%$ of the members of the U.S. Congress [1]. Among the many factors that have been examined to explain the dearth of women in leadership roles, including sexism and structural barriers, e.g., [2], are factors related to women's own career motivations and expectations for professional success. The current study focused on a subset of factors affecting young women's perceptions of themselves as leaders: exposure to counterstereotypical women role models, perceived similarity to these women, and information about these women's motherhood status.

\section{Theoretical Background}

\subsection{Gender Stereotypes and Women's Leadership}

One possible reason for the lack of equal representation of women in leadership positions, especially in counterstereotypic domains like the STEM fields, could be that traditional gender stereotypes about women are incompatible with these positions. Stereotypes of women emphasize communal traits and democratic leadership styles, while expectations of effective leaders emphasize agentic traits and authoritative leadership styles [3-4]. If a woman does demonstrate agentic counterstereotypic qualities, however, she may be viewed unfavorably because she is behaving in a role incongruent way [5-7]. For example, 
Rudman and Phelan [8] found that both men and women are likely to penalize women who exhibit counterstereotypic traits or who are successful in counterstereotypic fields. These female exemplars are deemed socially unattractive by both genders, creating a culturally shared perception of the backlash those who break stereotypes receive.

This negative stereotype of women leaders, and the negative social attention given to women who occupy this atypical role, can affect younger women's career aspirations. Research with college students indicates that both men and women viewed leadership and managerial roles as positive; however, women students viewed the positions as less possible than did their male counterparts [9-10]. Women students also ranked leadership positions in a stereotyped feminine industry (clothing) as more positive than those in the stereotyped masculine industry (auto manufacturing), likely because they viewed the latter industry as particularly role-incongruent [6].

\subsection{Changing Stereotypes: The Effects of Counterstereotypic Primes}

A number of studies have explored how to change stereotypes of women leaders as role incongruent. These studies distinguish between implicit (i.e., non-conscious) and explicit (conscious) attitudes. Researchers [11-13] provide evidence that reduction of implicit stereotypic associations can be achieved by strengthening counterstereotypic associations. Due to factors like social desirability bias, participants are often discouraged from explicitly sharing certain beliefs; for example, explicitly stating identification with traditional gender role stereotypes where women belong in the domestic sphere. Measuring implicit stereotypes and associations can bypass these intervening social and interpersonal effects. The Implicit Association Test (IAT) uses reaction time as a measure of how strongly various categories and target attributes are associated [14]. When the category and target attribute are very highly implicitly associated, the participant has a quicker response time classifying them. This is compared with a category and attributes that are not associated strongly, and is demonstrated by the participant's slower response times. Even if participants explicitly state that they do not buy into associations between categories, their implicit stereotypes will make some pairings of words easier to match than others.

Previous research has shown that these automatic unconscious implicit associations are sensitive to effects of priming [12]. Many have hoped that exposing women students to women exemplar primes can work to decrease their stereotypes regarding leadership. Actual findings relating to the ways in which exposure to primes of successful women exemplars impact women's stereotypes have been contradictory and nuanced. In some research, exposure to successful women primes led to increases rather than decreases in gender stereotypes [15-17]. For example, Rudman and Phelan [8] found that college women's exposure to primes of women vanguards led to a reduction in the association of the self with leadership, ambition and success. One possible reason for these findings is through the process of upward social comparison whereby participants exposed to successful women may feel inadequate by comparison [18]. This may be especially likely if the female participants have low levels of leadership self-efficacy [16-17] or believe that leadership qualities are innate rather than learned [19]. Another possible reason for these findings could be because the primes potentially activated the association of the backlash and negative social effects that participants could experience if they follow a similar nontraditional career path as the primes.

Other researchers, however, have found that in certain contexts, exposure to accomplished women can be beneficial and can decrease implicit gender associations [12, 20]. One of the key features necessary for exposure to exemplars to reduce implicit gender and leadership stereotypes is the perception that similar success is attainable for the participant $[19,21]$. In Dasgupta and Asgari's study [22], the more participants believed that other women, including themselves, could become as successful as the famous leaders, the less likely they were to express automatic gender stereotypes. Perceiving the success of famous female primes as attainable made seeing women leaders especially effective at reducing these implicit biases.

The current study was modeled on Experiment 2 of Asgari, Dasgupta and Stout's [3] research. In their work, 66 female undergraduates were told that during their participation they would complete a few unrelated tasks, starting with what was framed as a generalized knowledge test where they were shown 16 primes of successful females in nontraditional fields. Participants randomly received false feedback based on a fake personality test that suggested they either were similar to the successful women (strong in agentic traits), dissimilar (strong in communal traits), or no comment on similarity was given (control). Participants in all three conditions then completed both a self-IAT and an explicit measure of self-beliefs; both measures assessed the participants' associations between themselves and either leadership or supportive qualities as compared to men with the same qualities. Asgari et al. found that participants in the high-similarity condition exhibited counterstereotypic selfbeliefs as defined by their scores on the leadership self-IAT; these responses were significantly different from both the control and low-similarity condition. In fact, the researchers found that the scores of the participants in the low-similarity condition were significantly more stereotypic than the selfIAT scores of the control condition. These results suggest that perceived similarity to successful women role models can increase women's implicit associations between their own personality and leadership qualities. In terms of explicit associations with leadership qualities, only those who believed they were similar to the successful women role models increased the number of leadership qualities they explicitly associated with themselves.

The Asgari et al. [3] study (and other research by Dasgupta, [12]) is important because it demonstrates that 
participants' perceived similarity to counterstereotypic women role models used as primes could increase women's implicit associations between themselves and agentic (counterstereotypic) traits, whereas changing women's explicit associations required women consciously accepting the (false) feedback about similarity. One limitation of the research is that it ignores the effects motherhood concerns have on college women's career planning. Including information about the primes as mothers could enhance the degree to which participants find the primes relatable and similar and could enhance the impact the primes have on both implicit and explicit attitudes. This was the focus of the current study.

\subsection{Employed Mothers}

Compatibility of a career with family responsibilities is an important factor in women's career plans in ways it is not for men. American college women who said they valued family expect lower salaries than do men with similar attitudes [23]. Indeed, research has found these expectations to be realistic: being a parent decreases women's wages but increases men's wages [24]. The expectation of a motherhood penalty can become a self-fulfilling prophecy in that college students may not challenge the ideas that women deserve less pay or that women bear an unequal share of the domestic work [23]. These ideas have not changed much since the 1980's, despite the fact that the majority of mothers are in the labor force [25].

If women in leadership positions or in counterstereotypic fields are viewed as transgressive in terms of violating the general stereotype of women, mothers in these positions could be considered even more transgressive [26]. Hodges and Park [27] found that female college students perceived their identity as parent and professional as oppositional, while this was not true for male students. This research found that qualities of professionals and fathers overlapped more than those of professionals and mothers, highlighting the antagonistic nature of women's two main identities. Depending on which domain was primed, college women switched from one identity to the other; this constant switching depleted cognitive resources and complicated women's view of employed mothers, preventing an integrated self-concept.

Many employers and co-workers also view women's professional and maternal identities as incompatible. Employers judge working mothers using stricter standards than they do working fathers [28]. Women employees with children are perceived as both less committed and less competent than women employees who are not mothers, while men employees with children are thought of as more committed and actually receive pay increases [24, 29]. Additionally, employed mothers who work in traditionally masculine positions or fields were perceived to be less effective as parents than stay-at-home mothers [26]. These findings likely contribute to women's career choices if they also want to be mothers.

An important research question is whether providing information about the motherhood status of successful women would counteract the perceived incompatibility of these two identities for college women. On the one hand, depictions of a successful woman who is also a mother might convey that reconciliation of the two spheres is possible; therefore, such women might be particularly influential in disrupting negative leader self-stereotypes in college women [30]. On the other hand, such women may be viewed as particularly exceptional and therefore farther removed from the average college woman than when motherhood is not mentioned. It may only be when the similarity between the successful mother role models and the college women participants is emphasized that such role models encourage counterstereotypical attitudes. When such similarity is not emphasized, the stereotypical disjunction between motherhood and worklife success should leave selfleadership implicit attitudes unchanged. The current study tested this prediction.

\subsection{Current Study}

The current study aimed to replicate and extend the methodologies and findings of previous research on the effects of similarity to counterstereotypic female primes on college women's leadership stereotypes by including information about the primes' motherhood status as an additional variable. Utilizing the Asgari et al. [3] paradigm, the current study investigated how differences in implicit and explicit self-representation relative to leadership characteristics were related to the degree of perceived similarity between self and prime, particularly emphasizing either the female participants' agentic (counterstereotypical) personality traits, or communal (stereotypical) personality traits. Additionally, in a new vein of investigation, this study examined how the description of the exemplars as mothers affected the self-leadership associations both implicitly and explicitly.

The two independent variables were degree of similarity to the primes (similar/dissimilar using false feedback based on the Bem Inventory [31]) and information about the primes' motherhood status (present/absent.) As in Asgari et al. [3], the dependent variables were both implicit (self-leadership IAT) and explicit leadership traits. A control condition where participants were uninformed about their similarity to the primes was omitted since Asgari et al. found that it served primarily as a baseline. Because we were interested in how women's own associations with leadership would be affected by the independent variables, only women participants were used (similar to Asgari et al).

The hypotheses for the current study were:

1) There would be a main effect of similarity on implicit self-leadership stereotypes, such that women in the similar feedback conditions would have IAT results indicating more counterstereotypic implicit associations than those in the dissimilar feedback condition, whose IAT results would indicate more traditional leadership stereotypes. This hypothesis was based on the results of Asgari et al.'s [3] Experiment 2. 
2) The main effect of similarity would be qualified by an interaction with mother status information such that participants in the similar mother-mentioned condition would have implicit self-leadership IAT scores indicating least adherence to traditional gender stereotypes and the most counterstereotypical associations. Because college women identify with their future possible selves as mothers [27] and because motherhood status can reduce backlash effects for female leaders [30], being told they were similar to successful women who were mothers was expected to lead to more counterstereotypical implicit self-leadership attitudes than would occur in the other three conditions (dissimilar mother-mentioned, dissimilar mother-not mentioned, similar mother-not mentioned). That is, those who were told they were similar to successful women who were mothers would be the group most likely to associate themselves with the agentic traits typical of leaders. No main effect of motherhood status was expected.

3) Explicit self-leadership stereotypes would change in a counterstereotypical direction only if participants accepted the feedback they were given in the two similar conditions, similar to the results found in Asgari et al.'s [3] Study 2. This pattern would be particularly marked in the similar mothermentioned condition.

\section{Method}

\subsection{Participants}

Eighty-seven female students participated in the $2 \times 2$ study, with approximately 20 participants per condition. Participants were students majoring in various academic disciplines (34 natural sciences, 30 social sciences, 11 humanities, 7 engineering, 4 other) at a small liberal arts college in the northeast, from various class years $(29 \%$ freshmen, 30\% sophomores, $17 \%$ juniors, $24 \%$ seniors). Participants were recruited through word of mouth and through their psychology classes to earn extra credit for completing the experiment, which was presented as a study of the relationship between personality traits and how women think about and relate to leaders and leadership.

\subsection{Materials}

\subsubsection{Primes}

The primes used in the study were selected from a broader list of women leaders in a pilot study that reduced a list of 16 possible primes to a final group of six. Twenty-one college women answered questions related to familiarity, likeability, perceived level of success, and knowledge of the prime's motherhood status. The six final primes (Abby Cohen, Eileen Collins, Marian Wright Edelman, Indra Nooyi, Sheryl Sandberg, Susan Wojcicki) were chosen to include a group matched on the measured variables (relatively unfamiliar, no knowledge of prime's motherhood status, average likeability, and above average perceived level of success) and who represented a range of fields, ages, and ethnicities. (It should be noted that the study was conducted in 2015 before Sheryl
Sandberg became well known.).

During the study, the vignettes paired with the final six primes included a brief biographical description of each woman's achievements and either mentioned their status as a mother or contained no mention of their motherhood status. (All the primes had at least one child.) The mother-notmentioned conditions were similar to the experimental conditions used by Asgari et al [3].

\subsubsection{Prime Checks}

Questions were asked to assess participants' perception of the women leaders on multiple dimensions on 5-point scales $(1=$ extreme disagreement, $5=$ extreme agreement $)$. Participants completed measures rating the extent to which they were familiar with the primes, liked the primes, and how alike they thought they were to the primes. Participants completed ratings of how important having children and a successful career was to them and how possible and positive they think it would be for themselves or someone like them to attain a similar level of success as the primes. They also rated their admiration for and perception of how successful they thought the primes were.

\subsubsection{Memory Test}

A fake memory test was administered about the content associated with each prime in order to re-expose participants to the primes. For each prime, a question about her status as a mother was asked. A multiple-choice question was asked where participants had to match the prime to her correct vignette. Over half $(\mathrm{N}=45)$ of the participants correctly matched all of the primes to their descriptions. Thirteen participants misidentified one prime's description, 16 misidentified two primes' descriptions, three answered correctly for half of the primes, one participant only correctly matched two primes to their descriptions, and one participant only correctly matched one prime. Although many participants did answer portions of the memory test incorrectly, the purpose of the exposure to the primes was not contingent on participants' memory of the specific information related to each prime. Instead, what was posed to the participants as a memory test was essentially another priming activity, which allowed participants to be exposed to the primes' characteristics, achievements, and, when applicable, their status as mothers, for a second time. Therefore, no data were removed from the final analyses, even if participants answered incorrectly during the test section where they were instructed to match the prime to her correct vignette.

\subsubsection{Bem Inventory}

Participants completed the short version of the Bem Inventory [31] which asked participants to rate how well 30 personality characteristics described them on a 7-point scale $(1=$ never or almost never true, $7=$ always or almost always true). The Inventory yields two scores: a "Masculinity" score based on the average of 10 agentic traits (defend my own beliefs, independent, assertive, willing to take a stand, aggressive, strong personality, forceful, have leadership 
abilities, willing to take risks, dominant $)(\alpha=.91)$; and a "Femininity" score based on the average of 10 communal traits (affectionate, sympathetic, sensitive to the needs of others, understanding, compassionate, warm, love children, gentle, eager to soothe hurt feelings, tender $)(\alpha=.93)$. The Bem Inventory was used because it is a measure of personality traits similar to the feedback and the implicit and explicit measures used later in the experiment. Additionally, because the Bem Inventory uses number ratings, it was plausible that the feedback participants received after completing the inventory was actually calculated by the computer from their self-ratings.

\subsubsection{Feedback}

Participants were told either that their results on the Bem Inventory indicated that they had gender counterstereotypic qualities (similar conditions) or that they had gender stereotypic qualities (dissimilar conditions). Descriptions were identical to those used by Asgari et al. [3]. Similar personality feedback emphasized participants' agentic traits:

"You are quite similar to the women leaders you read about earlier. Specifically, you are quite likely to achieve a similar kind of success as the women leaders in your own professional life. You can be best described as an ambitious and highly motivated individual who strives for achievement. You are best suited for leadership positions and are capable of becoming a pioneer in your professional field. You are capable of influencing others and holding a powerful post within an organization."

Dissimilar personality feedback emphasized participants' communal traits:

"You are quite different from the women leaders you read about earlier. Specifically you are not likely to achieve a similar kind of success as the women leaders in your own professional life. Rather, you can be best described as a nurturing individual who is willing to give other peoples' needs priority. You are kind and gentle toward others and are best suited for supportive positions in which you can best utilize your considerate and sympathetic nature. You are capable of expressing great sensitivity and providing a harmonious environment in your workplace."

Participants' perception of the feedback was measured with manipulation check questions that asked participants to rate how accurate the feedback was, indicate their desire for the feedback to be true and the likelihood that the feedback would be true of them in the future, and the importance of being defined this way, measured on 5-point scales $(1=$ extreme disagreement, 5 = extreme agreement). Responses to these four manipulation check questions were averaged to create a measure of general feedback acceptance $(\alpha=.87)$.

\subsubsection{IAT}

The IAT was run on the program DirectRT (Version 2012.4.0.166; Empirisoft Corporation; New York, NY). It was a self-leadership IAT, where participants were asked to match target words with first-person or third-person male pronouns, as used bv Asgari et al. [3]. This procedure ensured that participants were comparing their self-leadership associations with those of the cultural ideal, stereotypically male, leader. The IAT used leader (leader, ambitious, assertive, achiever, successful) and supporter (supporter, helpful, sensitive, considerate, understanding) target words which were matched to either the first- or third-person pronoun categories.

The participants' reaction times in matching the target words to categories were combined to calculate IAT $D$ scores, indicating the extent to which their leadership selfrepresentations were more or less stereotypical. IAT $D$ scores were computed by subtracting the mean latency (reaction time) of responses in the stereotypical matching block from the mean response time in the counterstereotypical matching block, and dividing by the pooled standard deviation of all response times in the critical blocks for each participant. This method was taken from Asgari et al.'s [3] Experiment 2 transformation of IAT data into $D$ scores. Positive IAT $D$ scores indicate stereotypical self-associations of the participant and communal/supporter traits; negative IAT $D$ scores indicate counterstereotypical self-associations with agentic/leader traits.

\subsubsection{Explicit Measure}

The explicit measure asked participants to rate the extent to which each of the five leader and five supporter words used in the IAT described themselves as compared to men on the same 7-point scale as the Bem Inventory $(1=$ never or almost never true, 7 = always or almost always true). As did Asgari et al. [3], two scores were computed: an average explicit counterstereotypical agentic/leader score $(\alpha=.84)$ and an average explicit stereotypical communal/supporter score $(\alpha=.80)$.

\subsubsection{Demographics}

The demographic questionnaire consisted of questions related to class year, major, and future career.

\subsection{Procedure}

Participants were randomly assigned to one of the four feedback x mother conditions (similar mother-mentioned, similar mother-not-mentioned, dissimilar mother-mentioned, dissimilar mother-not-mentioned). To begin the study, participants completed the informed consent form and used Qualtrics [32] to take the rest of the questionnaires, beginning with exposure to the six primes.

Each participant was shown the same six primes of women leaders, whose vignettes described their achievements and, depending on the condition, a description of their motherhood status. The information for each prime was presented separately on screen, and after reading, the participant advanced to the next prime. After seeing each of the primes, the participants were told that to help them remember they would be asked to answer questions describing what they thought about the primes (prime checks). Once they finished the questions, participants completed the fake memory test about the content of the biographies shown in the primes. 
Next, the participants were instructed to complete a short personality test. Participants were told that they would be completing the Bem Inventory which measures personality traits, and that their scores would be used to give them feedback about their personality characteristics. Participants received one of the two possible feedback briefs, indicating their level of (dis)similarity to the primes and their possession of stereotypical/communal or counterstereotypical/agentic personality traits. They then completed the manipulation check questions, indicating the extent to which they accepted the feedback.

While the first half of the study was presented as trying to measure how participants view women leaders, the second half was presented as designed to measure how participants perceive leadership. The order of the self-IAT and the explicit measure were counterbalanced across participants. For the self-IAT, the experimenter started the IAT program and participants saw instruction screens that told them to take the test as quickly as possible without making any mistakes. After the participants were introduced to the IAT and read through the instruction screens, the data collection section of the IAT began. For the explicit measure, participants were told to answer a few questions about the words used in the IAT, and participants ranked the extent to which they believe the target words describe themselves as compared to the average man.

The demographic measure was always given last. At the end of the session, participants were partially debriefed. Full debriefing occurred following the conclusion of data collection, approximately six weeks later. The randomized and fictitious nature of the feedback each participant received was highlighted.

\section{Results}

Univariate ANOVAs showed that there were no significant differences between the conditions in terms of how participants rated the primes on their answers to any of the prime checks, or their performance on the memory test. Bem Masculinity and Femininity scores also did not vary by condition.

\subsection{Implicit Beliefs About the Self}

A factorial ANOVA was run to examine the effect of similarity and mother status on IAT $D$ scores. There was a main effect of similarity, $F(1,83)=7.98, p=.01, \eta^{2}=.09$, and the interaction approached significance, $F(1,83)=2.33$, $p=.06, \eta^{2}=.04$. There was no main effect of mother status. Participants in the similar mother-mentioned condition had counterstereotypic self-leader associations, while those in the similar mother-not-mentioned condition, the dissimilar mother-not-mentioned, and dissimilar mother-mentioned condition had stereotypic self-leader associations (see Table 1). A correlation matrix was generated to determine which measures, if any, correlated with IAT $D$ scores (see Table 2). Because Bem Masculinity scores correlated significantly with the IAT $D$ Scores, $r=-.45, p<.01$, a covariate ANOVA was run which used Bem Masculinity scores as a covariate. Although there were no group differences in the correct matching of the primes to their biographies, performance on the fake memory test was also used as a covariate. This was done in case poor performance on the memory test was related to the attention participants paid to the rest of the study, specifically the personality feedback and implicit and explicit measures. This ANCOVA revealed a significant main effect of similarity, $F(1,81)=3.12, p=.02, \eta^{2}=.07$, and a significant interaction of similarity and mother status, $F(1$, $81)=2.31, p=.04, \eta^{2}=.05$ (see Figure 1 ). The calculated group means were slightly different when the covariates were included, but the order of the conditions' means did not change (see Table 1).

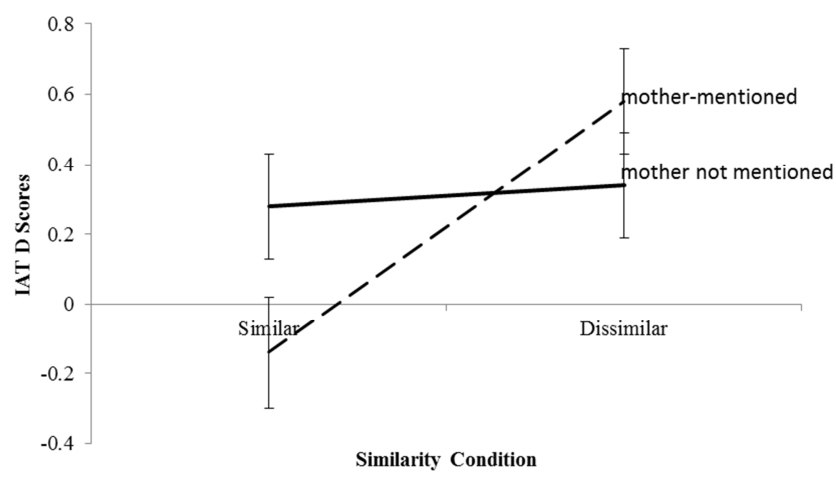

Figure 1. Interaction between similarity condition and mother-mentioned condition, using mean IAT D scores. Negative scores indicate counterstereotypic self-associations with leadership stereotypes; positive scores indicate stereotypic self-associations. Error bars represent standard error.

Table 1. The Effect of Prime Condition on Implicit and Explicit Scores and Feedback Acceptance (Means and Standard Deviations).

\begin{tabular}{|c|c|c|c|c|c|c|c|c|}
\hline \multirow[t]{2}{*}{ Measure } & \multicolumn{2}{|c|}{$\begin{array}{l}\text { Similar Mother- } \\
\text { Mentioned }\end{array}$} & \multicolumn{2}{|c|}{$\begin{array}{l}\text { Similar Mother-Not- } \\
\text { Mentioned }\end{array}$} & \multicolumn{2}{|c|}{$\begin{array}{l}\text { Dissimilar Mother- } \\
\text { Mentioned }\end{array}$} & \multicolumn{2}{|c|}{$\begin{array}{l}\text { Dissimilar Mother-Not- } \\
\text { Mentioned }\end{array}$} \\
\hline & $M$ & $S D$ & $M$ & $S D$ & $M$ & $S D$ & $M$ & $S D$ \\
\hline IAT $D$ Score & -.20 & .51 & .25 & .83 & .61 & .82 & .40 & .94 \\
\hline $\begin{array}{l}\text { IAT } D \text { Score (BEM Masculinity and } \\
\text { Memory Performance as covariate) }\end{array}$ & $-.14_{\mathrm{a}}$ & .16 & $.28_{\mathrm{ab}}$ & .16 & $.58 \mathrm{~b}$ & .15 & $.34_{\mathrm{b}}$ & .15 \\
\hline Explicit Leader Score & 5.54 & .92 & 5.67 & .93 & 5.73 & .79 & 5.52 & 1.03 \\
\hline Feedback Acceptance & $4.19 \mathrm{a}$ & .52 & $4.11_{\mathrm{a}}$ & .67 & $2.86_{\mathrm{b}}$ & 1.03 & $2.97 \mathrm{~b}$ & .98 \\
\hline
\end{tabular}

Note: Means with different subscripts are significantly different, $\mathrm{p}<.05$. Negative IAT D Scores indicate counterstereotypic self-leader associations, positive scores indicate stereotypic self-leader associations. Explicit Leader scores are on 1-5 scale, with higher scores indicating more identification with the leader traits. Feedback Acceptance scores are on a 1-5 scale, with higher scores indicating greater acceptance of the personality feedback. 
To determine which means were different, a univariate ANCOVA was run comparing the four conditions' IAT $D$ scores with BEM Masculinity and memory performance as covariates. Results indicated that the similar mothermentioned condition was significantly different than both the dissimilar mother-mentioned $(p<.05)$ and the dissimilar mother-not-mentioned condition $(p=.03)$. The similar mother-not-mentioned was not significantly different than both dissimilar conditions $(p>.05)$. The difference between the two similar conditions was not significant, but trended towards significance $(p=.07)$.

\subsection{Explicit Beliefs About the Self}

A factorial ANOVA was conducted to determine if either of the two manipulations had an effect on participants' explicit identification with the leadership traits. The ANOVA showed that the main effect of similarity was not significant, $F(1,83)=.01, p=.94, \eta^{2}<.01$; neither was the main effect of motherhood status, $\left.F(1,83)=.04, p=.84, \eta^{2}<.01\right)$. The interaction also was not significant, $F(1,83)=.74, p=.39$, $\eta^{2}=.01$ (see Table 1). As shown in Table 2, there were significant correlations between explicit leader scores and ratings of career importance, $r=.32, p<.05$, and Bem Masculinity scores, $r=.78, p<.05$. An ANCOVA was run with these two variables plus memory performance as covariates, but the results were not significant (similarity, $F$ $(1,80)=2.14, p=.15, \eta^{2}=.03$; motherhood status, $F(1,80)$ $=.24, p=.63, \eta^{2}<.01 ;$ similarity $\mathrm{x}$ motherhood interaction $F$ $(1,80)=2.36, p=.13, \eta^{2}=.03$. Explicit self-leader stereotypes were not affected by either of the two manipulations for any of the four conditions.

Table 2. Correlations of IAT D Scores and Explicit Leader Scores with Other Measures (Means and Standard Deviations).

\begin{tabular}{lllll}
\hline Measures & $\boldsymbol{M}$ & $\boldsymbol{S D}$ & IAT $\boldsymbol{D}$ Scores & Explicit Leader Score \\
\hline Career Importance & 4.70 & .68 & -.07 & -.04 \\
Children Importance & 4.34 & .96 & $-.45^{*}$ & $.32^{*}$ \\
BEM Masculinity & 4.77 & .95 & .14 & $.78^{*}$ \\
BEM Femininity & 5.51 & .89 & -.15 & -.04 \\
Feedback Acceptance & 3.51 & 1.04 & $-.23^{*}$ & .02 \\
Prime Familiarity & 1.78 & 1.03 & -.01 & .01 \\
Prime Like & 4.44 & .74 & -.11 & .06 \\
Prime Alike & 3.30 & .85 & -.08 & $.54 *$ \\
Prime Possible & 3.72 & .90 & -.13 & $.41^{*}$ \\
Prime Positive & 3.74 & .92 & -.16 & .14 \\
Prime Admire & 4.61 & .54 & -.12 \\
Prime Success & 4.94 & .23 & -.08 \\
\hline
\end{tabular}

Note: Bem ratings are on 1-7 scales, with 7 indicating high values; other scores are on 1-5 scales, with 5 indicating high values. Negative IAT D Scores indicate counterstereotypic self-leader associations. *Pearson correlation $p<.05$ level, 2-tailed.

\subsection{Impact of Feedback Acceptance}

Following the results of Asgari et al. [3], further analyses were conducted to examine whether the degree to which participants accepted the feedback they were given had an effect on their self-stereotypes, both implicit and explicit.

A factorial ANOVA was run to determine whether or not feedback acceptance was affected by similarity or motherhood status. There was a significant main effect of similarity, $F(1,83)=47.89, p<.01, \eta^{2}=.37$, but no main effect of motherhood status, $F(1,83)=.01, p=.92, \eta^{2}<.01$; or of their interaction, $F(1,83)=.29, p=.59, \eta^{2}<.01$. Participants in the similar conditions $(M=4.15, S D=.60)$ indicated significantly greater feedback acceptance than those in the dissimilar conditions $(M=2.92, S D=1.00)$ (see Table 1).

Following Asgari et al. [3], a linear regression was calculated to determine if the participants' change in implicit stereotypes was related to their acceptance of the feedback. The linear regression used condition, feedback acceptance, and the interaction term as predictors of the outcome variable, IAT $D$ scores. There was no main effect of condition, $\beta=-.81, S E=.39, p=.13$, but there was a main effect of feedback acceptance, $\beta=-.77, S E=.31, p=.05$, and the interaction was significant, $\beta=.98, S E=.10, p=.03$. To investigate the interaction further, regression analyses were performed separately for each of the four conditions, using feedback acceptance as the predictor of IAT $D$ scores. Feedback acceptance was a significant predictor of implicit self-stereotypes for the similar mother-not-mentioned condition, $\beta=-.46, S E=.25, p=.03$, and for the dissimilar mother-mentioned condition, $\beta=.44, S E=.16, p=.04$. Higher feedback acceptance predicted counterstereotypic self-leader beliefs in the similar mother-not-mentioned condition, but stereotypic self-leader beliefs in the dissimilar mother-mentioned condition. Feedback acceptance was not a significant predictor of IAT $D$ scores in the similar mothermentioned condition, $\beta=-.16, S E=.22, p=.50$, or the dissimilar mother-not-mentioned condition, $\beta=.06, S E=.22$, $p=.79$.

Additionally, a linear regression was run to determine whether the participants' explicit self-leader stereotypes were influenced by the type of feedback they received and the degree to which they accepted the feedback. The regression was conducted using condition, feedback acceptance, and the interaction term as predictors of the outcome variable, explicit leader scores. Both feedback acceptance, $\beta=1.05$, $S E=.35, p=.01$, and condition, $\beta=1.46, S E=.44, p=.01$, 
had significant effects, and the interaction term was also significant, $\beta=-1.28, S E=.11, p=.01$. To investigate the interaction further, separate regressions were run for each of the four conditions to determine how the influence of the participants' acceptance of the feedback depended on the condition. Feedback acceptance was a significant predictor in both the similar mother-not-mentioned, $\beta=.80, S E=.19, p$ $<.01$, and dissimilar mother-mentioned conditions, $\beta=-.43$, $S E=.16, p=.05$. Like the findings on the effect of feedback acceptance on implicit self-stereotypes, higher feedback acceptance predicted counterstereotypic self-leader associations in the similar mother-not-mentioned condition as well as stereotypic self-leader associations in the dissimilar mother-mentioned condition. Feedback acceptance was not a significant predictor of explicit self-leader associations in the similar mother-mentioned condition, $\beta=.35, S E=.38, p$ $=.12$, or the dissimilar mother-not-mentioned condition, $\beta=$ $-.22, S E=.23, p=.33$.

\section{Discussion}

As predicted, the results of the current study indicate that participants' implicit self-stereotypes were counterstereotypical only in the similar mother-mentioned condition, indicating greater identification of the self with agentic leader traits after being exposed to descriptions of successful women leaders described as similar and as mothers. Also as expected, explicit self-leader associations of the participants were not affected by either the manipulation of similarity or mother status. However, the more participants accepted feedback regarding (dis)similarity, the more likely both their implicit and explicit self-leader associations were to change in the manipulated direction in two conditions: the similar mother-not-mentioned condition, becoming more counterstereotypical; and the dissimilar mother-mentioned condition, becoming more stereotypical. The results partially support and extend the findings of Asgari et al. [3].

As Asgari et al. [3] found, college women who received feedback that their personality was similarly agentic to that of counterstereotypical women primes were most likely to indicate counterstereotypical implicit self-leader associations, whereas participants who were told they were dissimilar to the primes and more communal were most likely to indicate stereotypical implicit self-leader associations, supporting Hypothesis 1. Extending previous research, the addition of information about the primes' motherhood status enhanced the effects of the similarity feedback: counterstereotypical implicit self-leader associations only occurred in the similar mother-mentioned condition, while the most stereotypical self-leader associations occurred in the dissimilar mothermentioned condition although the two dissimilar conditions did not differ from each other. Thus, Hypothesis 2 was supported. As Dasgupta [12] and others [19, 21] have argued, perceived similarity is key to the effectiveness of counterstereotypical role models in changing implicit associations. When role models represent ways of being and behaving that are perceived as possible for the participant, they can disrupt stereotypic associations and encourage counterstereotypical ones. This explanation is supported in the current study by a pattern of correlations that indicates that the more participants rate themselves as like the primes and consider similar success as possible for themselves, the more counterstereotypic participants' explicit self-leader stereotypes.

In contrast to the results of Asgari et al. [3], participants in the similar mother-not-mentioned condition did not significantly change their implicit self-leader associations as compared to the other three conditions. Perhaps being asked about the primes' motherhood status in the memory test provoked a sense of difference between themselves and the primes for participants in the mother-not-mentioned condition. This possibility is supported by the finding that when those in the similar mother-not-mentioned conditioned accepted the feedback that they were similar to the primes, their implicit self-leader associations did change in a more counterstereotypic direction.

Regarding the explicit self-leader associations of the participants, the current study's results found that participants' explicit self-leader scores were not significantly influenced by either of the two manipulations, supporting previous research [3]. The brief presentation of the primes and the feedback information were enough to alter the implicit self-leader associations of the participants, but not their explicit ones. Previous investigations have suggested that more substantial dismantling of stereotypes or thorough presentation of counterstereotypical primes is necessary to significantly alter participants' explicit self-associations in regards to leadership traits [22]. In this study, as in Asgari et al.'s [3], only those participants who accepted the false feedback they received about their own agentic and communal traits were affected by the similarity manipulation, partially supporting Hypothesis 3. The motherhood status manipulation modulated these effects: feedback acceptance was a significant predictor of explicit self-leader scores only for the similar mother-not-mentioned and dissimilar mothermentioned conditions. The direction of the means suggest that participants who believed they had strong agentic traits similar to those of successful women primes who were presented without any mention of children were most likely to express explicit counterstereotypic self-leader associations. Perhaps mentioning the primes' motherhood status evoked the conflicting identities of "mother" and "professional" [27, 29] that mitigated the counterstereotypic effect of similarity. In contrast, accepting the feedback that they had strong communal traits and were dissimilar to successful women primes who were mothers caused participants to explicitly confirm stereotypic self-leader associations and the incompatibility of motherhood and professional success. These results should be viewed cautiously, however, since the sample size of those who accepted the dissimilar feedback was small.

Feedback acceptance also affected participants' implicit attitudes in identical ways as their explicit stereotypes: i.e., only for the similar mother-not-mentioned and dissimilar 
mother-mentioned conditions. Although participants in the similar mother-mentioned condition changed their implicit attitudes the most and in a counterstereotypic direction regardless of feedback acceptance, only those who accepted the similarity feedback when motherhood was not mentioned changed their attitudes in that direction. Since the participants had rated that having a career as well as a family was important to them, it may be that both aspects need to be mentioned for role models to be most effective in disrupting implicit stereotypic associations. Asgari et al. [3] had not found feedback acceptance to affect implicit attitudes, only explicit ones. It may be that the feedback in the current study, supposedly based on the Bem Inventory rather the short questionnaire regarding life goals used by Asgari et al., was more convincing to participants. Given the reduced sample size, however, these findings should be viewed as speculative.

The current study's results partially support and extend the findings of Asgari et al.'s [3] Experiment 2, despite slight methodological differences: only six rather 16 primes, use of the Bem Inventory to manipulate similarity feedback, the priming "memory" test. The significant correlation between Bem Masculinity and implicit self-stereotypes suggests that for participants who already describe themselves with agentic traits, the association of the self with those traits occurs more quickly or more strongly, which could have impacted the implicit self-leader associations. Because this experience was not affected by the study manipulations but by the personal characteristics of the participants, the effects of the conditions were clearer once the Bem Masculinity scores were controlled for as a covariate during the analysis of implicit self-leader associations. Hoyt [16] found similar results using a measure of leadership self-efficacy: only women with high levels of leadership self-efficacy were positively inspired by highly successful role models.

The samples used in the current study and in that of Asgari et al. [3], while consisting of college women, might have differed as well. The current study could have used a higher achieving sample of students at a more rigorous institution, which might explain the differences in explicit selfstereotype findings. For example, participants in the current study did not rate the possibility and positivity of the participants' success significantly differently, in contrast to previous research, which often found that college women perceive women exemplars' success as extremely positive but slightly less possible for themselves or someone like them [9]. Additionally, participants in the current study rated the importance of a future successful career significantly higher than the importance of having children in the future, although both of these measures were rated as somewhat or extremely important. It also is possible that the present participants, who knew they were signing up for a study of women's personality traits and leadership, might have been an atypically agentic sample; that is, they were relatively high in leadership self-efficacy to begin with [16]. The ways in which sample characteristics might contribute to the effectiveness of exposure to counterstereotypic primes merit additional research.

One possible limitation, as discussed in Asgari et al. [3], of providing the personality feedback to the participants is that the dissimilarity feedback might be perceived as more negative than the similar feedback. Evidence for this can be seen in the finding that participants in the similar conditions accepted the personality feedback significantly more than those in the dissimilar conditions. Especially for a sample of college women concerned with enhancing their potential future career success, receiving the dissimilarity feedback might have been upsetting and negative, which could explain why the similar feedback was accepted more readily. Although both types of feedback were worded with positively valenced qualities, they still might have differentially influenced the confidence or emotions of the participants beyond framing the primes as similar or dissimilar. One possible problematic aspect of the personality feedback might have been the very first sentence of each, which told participants they were either very likely or very unlikely to achieve a similar level of success as the primes in their professional careers. The reactions to the feedback could have been reactions to the statement regarding their probability of professional success more than the effect of emphasizing either the participants' communal/stereotypic or instrumental/counterstereotypic personality traits. That is, the dissimilarity manipulation may have evoked a threat to the students' identity rather than degree of identification with the presented female role models. Future studies investigating the effect of (dis)similar personality feedback should explore this further. Pilot studies could be conducted to determine if participants' emotional reactions to the types of feedback are different, and should determine if similar patterns of responses result from feedback with just a prediction of future success or with just an emphasis on personality characteristics.

Another limitation of not only the current study but others which present participants with female exemplars is presenting primes whose success or field is not in line with the interests of the participants. This study attempted to provide variation in career type and field but four of the six primes were either CEOs, COOs, or otherwise involved in the upper levels of corporate management positions. While the exemplars all have different backgrounds and their academic training varied from (law, the military, engineering, business, economics), these backgrounds could have been emphasized more clearly. Participants who have no interest in becoming involved in the upper-level management of large corporations or who viewed the majority of the primes as in business or economics might not have been able to relate to the primes as well or might not have been as influenced or inspired by their success. The problem with finding a more varied group of successful primes may be due to our culture's definition of success and leadership. The ethnic and racial diversity of the primes also could be improved in order to enhance the possibility of participants relating to the primes.

Overall, this study adds to the research literature clarifying under which conditions successful female role models can 
lead to positive self-leadership attitudes in young women. As other researchers have found, mere exposure to successful women is not sufficient; the key seems to be participants' perceived similarity to the models $[3,12,16,19,21]$. A novel contribution of this study is the finding that perceived similarity to successful women who are mothers may be particularly effective for young women. Successful women often deliberately keep their work and family statuses separate because of strong negative attitudes in the workplace toward working mothers [24, 26, 28]. Paradoxically, however, mention of such combined identities may be what facilitates attitude change in a positive direction, at least among young women. Because of the strong traditional disjunction for young women between career aspirations and motherhood [27], young women may need to see exemplars of how the two identities can be combined successfully before they can see themselves as prospective leaders. How successful women role models might affect men's attitudes is a topic in need of further study. It may well be that exposure to successful women who also are mothers may lead to an increase in negative attitudes to working mothers, at least among men who feel that their dominant status is threatened by such changes; e.g., [33].

As is the case with other studies that attempt to change participants' implicit stereotypes, the question can be raised whether such efforts, even when successful in an experimental setting, have a long-term effect or are related to actual changes in behavior (see [34]). Although stereotypical implicit attitudes often are correlated with discriminatory behavior, there is an absence of causal evidence. More research clearly is needed on this topic. Nonetheless, exposure to a diversity of potential role models of leaders, including women of varied race/ethnicities and motherhood statuses, can serve to challenge the stereotype that only men can be leaders $[12,20]$.

\section{Conclusion}

The current study's results indicate that exposure to counterstereotypical role models can change young women's implicit self-leadership associations in a counterstereotypical direction if the participants believe they are similar to the role models and if information about the women's status as mothers is included. Perceived similarity to successful women may also change explicit stereotypes, but only among those who believe they actually possess agentic traits. These results support efforts to increase girls' and young women's exposure to successful women role models, especially in non-traditional fields, in order to increase the numbers of women in future leadership positions. The results of this study as well as previous research suggest when such exposure occurs, female viewers need to believe that similar success is attainable for themselves. Thus the role models' similarity to the viewers and their ability to combine careers and motherhood needs to be emphasized. It should be noted, however, that although increasing young women's associations between themselves and leadership qualities is important, achieving gender parity in leadership roles will require action on societal and structural levels as well.

\section{References}

[1] Warner, Judith, \& Corley, Danielle. (2017, May 21). The women's leadership gap: Women's leadership by the numbers. Center for American Progress.

https://www.americanprogress.org/issues/women/reports/2017 /05/21/432758/womens-leadership-gap/.

[2] Chira, Susan. (2017, July 21). Why women's aren't C. E. O.s, according to women who almost were. New York Times. Retrieved from https//nyti.ms/2tvCdj3, 7/21/17.

[3] Asgari, Shaki, Dasgupta, Nilanjana, \& Stout, Jane. (2012). When do counterstereotypic ingroup members inspire versus deflate? The effect of successful professional women on young women's leadership self-concept. Personality and Social Psychology Bulletin, 38, 370-383. doi: 10.1177/0146167211431968.

[4] Randsley de Moura, Georgina, Leicht, Carola, Leite, Ana C., Crisp, Richard J., \& Gocłowska, Malgorzata A. (2018). Leadership diversity: Effects of counterstereotypical thinking on the support for women leaders under uncertainty. Journal of Social Issues, 74, 165-183. doi: 10.1111/josi.12262.

[5] Caleo, Suzette, \& Heilman, Madeline E. (2014). Is this a man's world? Obstacles to women's success in male-typed domains. In Ronald J. Burke and Debra A. Major (Eds.), Gender in organizations: Are men allies or adversaries to women's career advancement? (pp. 217-233). Northampton, MA, US: Edward Elgar Publishing.

[6] Eagly, Alice H., \& Karau, Steven J. (2002). Role congruity theory of prejudice toward female leaders. Psychological Review, 109(3), 573-598. doi: 10.1037/0033-295X.109.3.573.

[7] Johnson, Stefanie K., Murphy, Susan E., Zewdie, Selamawit, \& Reichard, Rebecca J. (2008). The strong, sensitive type: Effects of gender stereotypes and leadership prototypes on the evaluation of male and female leaders. Organizational Behavior and Human Decision Processes, 106, 39-60. doi: 10.1016/j.obhdp.2007.12.002.

[8] Rudman, Laurie, \& Phelan, Julie. (2010). The effect of priming gender roles on women's implicit gender beliefs and career aspirations. Social Psychology, 41, 192-202. doi: 10.1027/18649335/a000027.

[9] Killeen, Lauren A., Lopez-Zafra, Esther, \& Eagly, Alice H. (2006). Envisioning oneself as a leader: Comparisons of women and men in Spain and the US. Psychology of Women Quarterly, 30, 312-322. doi: 10.1111/j.1471-6402.2006.00299.x.

[10] Sheppard, Leah D. (2018). Gender differences in leadership aspirations and job and life attribute preferences among U.S. undergraduate students. Sex Roles, 79, 565-577. Doi: 10.1007/s11199-017-0890-4.

[11] Blair, Irene V., Ma, Jennifer E., \& Lenton, Alison P. (2001). Imagining stereotypes away: The moderation of implicit stereotypes through mental imagery. Journal of Personality and Social Psychology, 81, 828-841. doi: 10.1037/00223514.81.5.828. 
[12] Dasgupta, Nilanjana. (2013). Implicit attitudes and beliefs adapt to situations: A decade of research on the malleability of implicit prejudice, stereotypes, and the self-concept. Advances in Experimental Social Psychology, 47, 233-279. doi: 10.1016/B978-0-12-407236-7.00005-X.

[13] Shin, Jiyun E. L., Levy, Sheri R., \& London, Bonita. (2016). Effects of role model exposure on STEM and non-STEM student engagement. Journal of Applied Social Psychology, 46, 410-427. doi: $10.1111 /$ jasp.12371.

[14] Greenwald, Anthony G., \& Banaji, Mahzarin R. (1995). Implicit social cognition: Attitudes, self-esteem, and stereotypes. Psychological Review, 102, 4-27. doi: 10.1037/0033295X.102.1.4.

[15] Betz, Diana, \& Sekaquaptewa, Denise. (2012). My fair physicist? Feminine math and science role models demotivate young girls. Social Psychological and Personality Science, 3, 738-746. doi: 10.1177/1948550612440735.

[16] Hoyt, Crystal L. (2013). Inspirational or self-deflating: The role of self-efficacy in elite role model effectiveness. Social Psychological and Personality Science, 4, 290-298. doi: 10.1177/1948550612455066.

[17] Hoyt, Crystal L., \& Simon, Stefanie. (2011). Female leaders: Injurious or inspiring role models for women?. Psychology of Women Quarterly, 35(1), 143-157. doi: $10.1177 / 0361684310385216$.

[18] Knobloch-Westerwick, Silvia, Kennard, Ashley R., Westerwick, Axel, Willis, Laura E., \& Gong, Yuan. (2014). A crack in the crystal ball? Prolonged exposure to media portrayals of social roles affect possible future selves. Communication Research, 41, 739-759. doi: $10.1177 / 0093650213491113$.

[19] Hoyt, Crystal L., Burnette, Jeni L., \& Innella, Audrey N. (2012). I can do that: The impact of implicit theories on leadership role model effectiveness. Personality and Social Psychology Bulletin, 38, 257-268. doi: $10.1177 / 0146167211427922$.

[20] Simon, Stefanie, \& Hoyt, Crystal L. (2012). Exploring the effect of media images on women's leadership selfperceptions and aspirations. Group Processes \& Intergroup Relations, 16, 232-245. doi: 10.1177/1368430212451176.

[21] Morgenroth, Thekla, Ryan, Michelle K., \& Peters, Kim. (2015). The motivational theory of role modeling: How role models influence role aspirants' goals. Review of General Psychology, 19, 465-483. doi: 10.1037/gpr0000059.

[22] Dasgupta, Nilanjana, \& Asgari, Shaki. (2004). Seeing is believing: Exposure to counterstereotypic women leaders and its effect on the malleability of automatic gender stereotyping. Journal of Experimental Social Psychology, 40, 642-658. doi: 10.1016/j.jesp.2004.02.003.
[23] Lips, Hilary, \& Lawson, Katie. (2009). Work values, gender and expectations about work commitment and pay: Laying the groundwork for the "motherhood penalty"? Sex Roles, 61, 667-676. doi: 10.1007/s11199-009-9670-0.

[24] Correll, Shelley, Benard, Stephen, \& Paik, In. (2007). Getting a job: Is there a motherhood penalty? American Journal of Sociology, 112, 1297-1339.

[25] Goldberg, Wendy, Kelly, Erin, Matthews, Nicole, Kang, Hannah, Li, Weilin, \& Sumaroka, Mariya. (2012). The more things change, the more they stay the same: Gender, culture, and college students' views about work and family. Journal of Social Issues, 68, 814-837.endy.

[26] Okimoto, Tyler, \& Heilman, Madeline. (2012). The "bad parent" assumption: How gender stereotypes affect reactions to working mothers. Journal of Social Issues, 68, 704-724. doi: 10.1111/j.1540-4560.2012.01772.x.

[27] Hodges, Allegra, \& Park, Bernadette. (2013). Oppositional identities: Dissimilarities in how women and men experience parent versus professional roles. Journal of Personality and Social Psychology, 105, 193-216. doi: 10.1037/a0032681.

[28] Fuegen, Kathleen, Biernat, Monica, Haines, Elizabeth, \& Deaux, Kay. (2004). Mothers and fathers in the workplace: How gender and parental status influence judgments of jobrelated competence. Journal of Social Issues, 60, 737-754. doi: 10.1111/j.0022-4537.2004.00383.x.

[29] Aranda, Beatriz, \& Glick, Peter. (2014). Signaling devotion to work over family undermines the motherhood penalty. Group Processes \& Intergroup Relations, 17, 91-99. doi: $10.1177 / 1368430213485996$.

[30] Heilman, Madeline E., \& Okimoto, Tyler G. (2007). Why are women penalized for success at male tasks?: The implied communality deficit. Journal of Applied Psychology, 92, 8192. doi: 10.1037/0021-9010.92.1.81.

[31] Bem, Sandra. (1974). The measurement of psychological androgyny. Journal of Consulting and Clinical Psychology, 42, 155-162. doi: 10.1037/h0036215.

[32] Qualtrics. (2014). Qualtrics (Version 2.017s) [Computer Software]. Provo, UT: Qualtrics.

[33] Danbold, Felix, \& Huo, Yuen J. (2017). Men's defense of their prototypicality undermines the success of women in STEM initiatives. Journal of Experimental Social Psychology, 72577266. doi: 10.1016/j.jesp.2016.12.014.

[34] Lai, Calvin K., Hoffman, Kelly M., \& Nosek, Brian A. (2013). Reducing implicit prejudice. Social and Personality Psychology Compass, 7, 315-330. doi: 10.1111/spc3.12023. 